\title{
Evoking a reciprocity of caring: Integration of humanities-based content into an interprofessional education immersion course for advanced practice nursing and health professions students
}

\author{
Margaret Brommelsiek * Heather J. Gotham, Jane A. Peterson \\ School of Nursing and Health Studies, University of Missouri-Kansas City, Kansas City, Missouri, USA
}

Received: April 20, 2016

DOI: $10.5430 /$ jnep.v6n9p110
Accepted: May 4, 2016

Online Published: May 17, 2016

URL: http://dx.doi.org/10.5430/jnep.v6n9p110

\begin{abstract}
Along with calls to train nurse practitioners to be full partners in healthcare and lead interprofessional collaborative practice teams, there have been calls to enhance health professions education to develop transformative learning experiences, teach the ability to critically observe patients and capture their narrative experience of health, and assist students to become more empathic and communicate more clearly. In a Health Resources and Services Administration-funded advanced nursing education project that included advanced practice nursing, dentistry, pharmacy and social work students, several humanities-based learning strategies were infused into an interprofessional curriculum that was paired with interprofessional collaborative practice at an urban, primary care clinic serving underserved patients with multiple chronic conditions. The current study analyzed qualitative data from focus groups and reflective journal entries regarding student perceptions of their interprofessional collaborative practice experience in the clinical setting following the humanities-based interprofessional curriculum. Four major themes were identified that relate to the humanities-based curriculum. Student participants gained confidence in their abilities as health providers, improved their methods of communication and focus with patients, learned how to negotiate ethical situations in support of patient-centeredness, and grew as members of interprofessional collaborative practice teams. Thus, the inclusion of the humanities into nursing and interprofessional education and practice can assist with strengthening presence, promoting moral imagination, and evoking a reciprocity of caring that can lead to improved patient care and outcomes.
\end{abstract}

Key Words: Humanities, Interprofessional, Nursing

\section{INTRODUCTION}

Problem-solving, moral reasoning, interpersonal communication, flexibility, leadership, and teamwork are highly valued as essential skills for preparing individuals for employment in contemporary work environments. ${ }^{[1,2]}$ Blaxell and Moore, ${ }^{[3]}$ proposed that curriculum design provide opportunities for students to develop the necessary skills and attributes that will be needed when they enter the workplace, and that curricular content include a variety of approaches in teaching these important proficiencies. In particular, the need to develop stronger interpersonal communication skills across the health professions has been identified, as poor communica-

*Correspondence: Margaret Brommelsiek; Email: brommelsiekm@umkc.edu; Address: School of Nursing and Health Studies, University of Missouri-Kansas City, 2464 Charlotte St., Kansas City, MO 64108, USA. 
tion between nurses and physicians is associated as a leading cause of increased mortality, length of hospital stays, and readmission rates. ${ }^{[4]}$ According to Andrew, ${ }^{[5]}$ nurses in particular find it difficult to express their contributions to the practice environment and Andrew and colleagues proposed that creating communities of practice, ${ }^{[6]}$ may be one way for nurses to construct professional identities and assist with bridging the divide between their academic and professional experiences. This is because interprofessional teams can promote a stronger sense of identity in each profession as they allow for a specific environment for defining one's place. ${ }^{[7]}$ Two Institute of Medicine reports ${ }^{[8,9]}$ reinforced the concept of interprofessional collaborative communities, calling for increased communication across the health professions, with advanced practice nurses as pivotal in leading interprofessional teams. ${ }^{[10]}$

The skills identified as important for employability in today's workplace environment also align with the fundamental attributes of the interprofessional education (IPE) core competencies, ${ }^{[11]}$ as each serves to enhance provider-patient relationships, improve communication, help in reducing fragmentation, and improve quality and safety in the delivery of healthcare services. ${ }^{[12,13]}$ According to Welch, ${ }^{[14]}$ "patientcentered care will call upon providers to not only understand the patient from a physiological sense, but possess the capacity to function from a humanistic stance that allows for interpretation and perception informed by ethical concern (p.23)." As the level of scientific and technical knowledge required to be an effective healthcare provider has increased exponentially in the past several decades, the burden of education for health professions students (what they need to know) has similarly increased. However, as always, healthcare providers need to find balance between the scientific and human values in building meaningful relationships with their patients $^{[15]}$ and peers. Therefore, preparing future nurses, nurse practitioners, and other health professionals for employability as members of interprofessional clinical practice teams (IPCP) will require developing an IPE curriculum that looks beyond the health sciences.

Quintero $^{[16]}$ suggested that health and illness be viewed as processes occurring across the healthcare continuum, and that an integrative approach for addressing the sociohumanism contained within these experiences can provide health professions students with opportunities to train together and improve their communication skills. Additionally, Frenk et al. ${ }^{[17]}$ identified a need within health professions education to establish transformative learning experiences that are designed to "develop leadership attributes to produce enlightened change agents" (p. 1933), and that entail a re-thinking about how the health professions are currently

Published by Sciedu Press taught. The delivery of quality healthcare is contingent upon complex factors coupled with an astute awareness that the provision of care necessitates both technical and interpersonal skills. ${ }^{[18]}$ A humanities-informed interprofessional curriculum goes beyond scientific, technical knowledge and skills about health and illness, and includes content and activities drawn from philosophy, communication, literature, and the arts and allows for immersion into the human experience $^{[19]}$ through collaborative engagement. ${ }^{[20]}$ Integrating humanities-based curriculum into traditional health sciences content can assist health professions students to fully comprehend the illness experience and its subsequent impact on patients' well-being, and may be an important strategy to fully shift our current health care system to patient-centered care.

Nursing practice and education have a long history of including the humanities. ${ }^{[21]}$ Humanities in nursing has been viewed as a way of promoting nurse leaders, ${ }^{[22]}$ fostering creative and critical thinking, and helping nursing students broaden their decision-making skills from a dualistic approach to a more holistic and inclusive perspective, while improving communication and mutual respect within the clinical setting. ${ }^{[23]}$ As evidence-based practice and technical knowledge become more prominent in the nursing curriculum, some believe an increase in the humanities is needed, as a scientific-only curriculum is inadequate in preparing nurses for practice in the clinical setting and for delivering patient-centered care. ${ }^{[24]}$ Lazenby $^{[25]}$ reported that the shift in nursing education to a predominantly evidence-based focus is in direct opposition to the very foundation of nursing practice, which is about the lives of humans and the illness experience. Like the other health professions, nursing has increasingly become more specialized and categorized. $\mathrm{Yu}^{[26]}$ noted that nurses' professional skills could be defined as discreet competencies of technical proficiency that produce verifiable results, but that do not speak to the human condition. The humanities help promote the human condition by requiring an ability to embrace unpredictability in experiencing human suffering while fostering attentive listening, communication, and mutual respect ${ }^{[27]}$ that are also attributes of interprofessional education and practice.

\subsection{Context}

This paper describes a project that expanded and enhanced the advanced practice nursing curriculum to teach nurse practitioner students to lead IPCP teams and improve fragmentation in healthcare delivery to persons with multiple chronic conditions. The project developed and implemented a humanities-based immersion course to prepare advanced practice nursing, dentistry, pharmacy, and social work stu- 
dents to work as IPCP teams in an urban-based clinic. The humanities-based curriculum focused on narrative practice, reflective thinking, enhanced awareness, and communication strategies to create person-centered healthcare.

\subsection{Humanities in healthcare}

Illness for humans is not just a physical phenomenon, but an event imbued with meaning, ${ }^{[28]}$ requiring health professionals to make care decisions based not only on immediate circumstances, but an ability to extrapolate into the future. The cornerstone of critical thinking is suspended judgment, and the impetus behind moral imagination that allows an individual to step ever so lightly away and to consider the "what if" of a situation (p. 28). ${ }^{[29]}$ Thus, fully understanding illness and the meaning contained within an illness event, requires an ability to fully comprehend a patient's experience through deep engagement with that individual's story. Stories define us as humans, and through our individual narratives we come to know and appreciate the experiences of others. In healthcare, this has particular relevance because in capturing a patient's narrative, the healthcare provider can access the entire illness experience. ${ }^{[30]}$

The inclusion of humanities-based subjects in health education provides multiple opportunities for health professions students to not only question in a non-reductive manner, but to critically and creatively identify solutions while stimulating their moral imagination from which altruism, empathy, respect, and integrity emerge. ${ }^{[31]}$ According to Fesmire, ${ }^{[32]}$ moral imagination is "the capacity to concretely perceive what is before us in light of what could be" (p. 65); a way of both seeing and feeling. The humanities in health education provide both affective and cognitive domains; ${ }^{[33]}$ affective, through acknowledging the role of emotions contained in provider-patient encounters, and cognitive, by fostering healthcare delivery as a practice involving an individual's intentionality, such as his/her experience of illness, along with creative problem-solving. ${ }^{[34]}$

Humanities subjects in health professions education have been identified as a method to improve patient-centered care, receiving endorsement from national organizations such as the American Association of Colleges of Nursing, the Association of American Medical Colleges, the Accreditation Council on Graduate Medical Education, the National Endowment for the Humanities, and the Society for Health and Human Values. Study of the humanities allows learners to wrestle with difficult moral dilemmas and develop humanistic approaches for working with patients. ${ }^{[21,35,36]}$ In becoming more empathic to the needs of their patients, communicating clearly about treatment options, and facilitating collaboration among other health professionals, health providers can improve access to care. ${ }^{[37]}$ Integrating these important attributes into health professions education may have particular application for helping to narrow the gap between provider-patient relationships and the de-humanization caused by increased technology within healthcare.

Common among concerns about technology in healthcare is provider reliance on advanced technologies as quick-fix solutions and extensive documentation during patient visits. ${ }^{[38]}$ Increased record-keeping has added stress to an already complicated healthcare environment, with nurses and physicians reporting insufficient time to manage both their patients and required clinical data. ${ }^{[39]}$ Nurses have struggled with finding balance between the provision of humane care and technology in the clinical setting, often viewing their role as both a bridge and mediator between two disparate forces. ${ }^{[40]}$ Technology in the clinical setting, especially exhaustive electronic documentation, has increasingly forced healthcare providers to choose between meticulous notation and spending already limited time engaging with their patients.

According to Weiner and Biondich, ${ }^{[39]}$ patient-centeredness in healthcare is contingent upon both the provider and the patient being willing to work, listen to one another, and negotiate a shared plan of care. In 2013, the Wall Street Journal asked an expert panel of healthcare providers how best to improve provider-patient communication, with the result including increased eye contact, active listening, and an ability to communicate clearly and concisely with patients. Additionally, the experts cited a need to remove assumptions and stereotypes in order to establish deep connections with patients. ${ }^{[41]}$ As healthcare continues to evolve, and patient populations are increasingly more diverse racially and medically, enhanced interpersonal communication, moral reasoning, and teamwork will be imperative in meeting patient expectations and providing patient-centered care as IPCP teams.

As humans, our well-being is tied to our empathic understanding of others. ${ }^{[42]}$ Therefore, when caring becomes absent, our relationships with others suffer. ${ }^{[43]}$ Humanities infused into IPE curricula can help establish common ground across the health professions while enhancing the delivery of care. ${ }^{[21]}$ For example, in nursing education, inclusion of the humanities has helped to elucidate the interconnectedness between technical application and clinical practice, ${ }^{[24,44]}$ and in medical education, to foster attributes of professionalism, cultural sensitivity, ethical reasoning, and empathic care. ${ }^{[43]}$ According to Schwartz et al. ${ }^{[45]}$ because the arts and humanities share attributes associated with empathic care, study of these subjects as part of health professions education can foster an obligation of compassion. 


\subsection{Curricular design and implementation}

Through an advanced practice nursing education grant from the Health Resources and Services Administration, an IPE curriculum was developed utilizing methods grounded in the humanities to teach advanced practice nursing, dentistry, pharmacy and social work students the IPE core competencies and best practices for providing care to medically underserved patients with multiple chronic conditions. The project also included a practicum experience in which nurse practitioner students were trained to lead IPCP teams of dentistry, pharmacy and social work students at an urban-based primary care clinic.

An executive committee comprised of faculty representatives from the four health professions schools developed criteria for student participants. Then, within each health professions school, faculty asked for students who would like to receive interprofessional education and work on interprofessional clinical practice teams in an urban clinic serving persons with multiple chronic conditions. The scope of the curriculum was not shared with the students during recruitment; therefore, the project was not biased by a humanities interest among the students selected to participate.

An eight-week IPE immersion course was offered in each of five academic semesters. In designing the curriculum, three competencies were identified as particularly essential to working with the patient population: enhanced interpersonal communication, ethical decision-making informed by values, and coordinated teamwork in the delivery of care. The decision to develop the curriculum content from humanitiesbased subjects was in response to the health professions being at risk of becoming de-humanized and to increase access for underserved patients. Inclusion of skill-building techniques, such as thoughtful reflection and practicing interpersonal communication, has been shown to increase confidence for working as members of interprofessional teams ${ }^{[20,46]}$ and may also help to eliminate perceived barriers between the patient and provider. ${ }^{[44]}$

The IPE immersion course curriculum utilized four key humanities-based approaches: reflective practice, a narrative approach with active listening, enhanced communication including mindfulness, and increased focus through employing visual art images to locate nuance (see Table 1). Each of these content areas was developed to enhance relationshipbuilding between provider and patient, and among providers as members of IPCP teams. Next we describe each approach and how it was used with students.

\subsubsection{Reflective practice}

Enhancing students' critical reflection skills is particularly important in healthcare as it serves two separate functions: comprehending the ways in which power can frame and skew processes, and collaborating with others through questioning assumptions and routines. ${ }^{[47]}$ Attributes associated with critical reflection include emotional grounding and increased trust. According to Ahlzén, ${ }^{[48]}$ when an individual is personally reflective, he/she may have a broader experience that not only fosters a nuanced view of the world, but one that can lead to moral maturity. During the semester, students were asked to use reflective journals. Each week they responded to a series of questions about their experiences with patients and other providers on the clinical rotation in support of the IPE core competencies (e.g., provide an example of how communication with other professionals went well or was a barrier [and if a barrier, what you did to help the situation]; provide an example of how you had to make a decision that called into question your own belief about something, or in which a colleague from another profession made a decision that you did not readily agree with, and how you negotiated the situation). This exercise allowed students to reflect on situations they encountered in the clinical setting and to openly describe their unique responses.

Table 1. Components of a humanities-based IPE immersion course

\begin{tabular}{|c|c|c|}
\hline $\begin{array}{l}\text { Humanities } \\
\text {-Based } \\
\text { Approach } \\
\end{array}$ & Modality & Purpose \\
\hline $\begin{array}{l}\text { Reflective } \\
\text { practice }\end{array}$ & Journaling & $\begin{array}{l}\text { To reflect on curricular content and } \\
\text { clinical practicum experiences in } \\
\text { relation to interprofessional core } \\
\text { competencies and develop } \\
\text { interpersonal communication and } \\
\text { moral reasoning skills }\end{array}$ \\
\hline $\begin{array}{l}\text { Narrative } \\
\text { approach }\end{array}$ & $\begin{array}{l}\text { Case studies and } \\
\text { role plays, } \\
\text { standardized } \\
\text { patients }\end{array}$ & $\begin{array}{l}\text { To develop interpersonal } \\
\text { communication skills by listening } \\
\text { to a patient's story and develop } \\
\text { empathic understanding for making } \\
\text { informed decisions and } \\
\text { patient-centered care plans }\end{array}$ \\
\hline Mindfulness & $\begin{array}{l}\text { Individual and } \\
\text { small group } \\
\text { exercises }\end{array}$ & $\begin{array}{l}\text { To increase presence with patients } \\
\text { and team members and develop } \\
\text { tools for negotiating team conflicts, } \\
\text { developing resilience, and caring } \\
\text { for self in stressful situations }\end{array}$ \\
\hline $\begin{array}{l}\text { Increased } \\
\text { focus }\end{array}$ & $\begin{array}{l}\text { Analyzing visual } \\
\text { art images }\end{array}$ & $\begin{array}{l}\text { To increase the ability to locate } \\
\text { nuance, use silence to be } \\
\text { reflective-in-action, and improve } \\
\text { communication and team } \\
\text { negotiation skills through } \\
\text { thoughtful dialogue. }\end{array}$ \\
\hline
\end{tabular}

\subsubsection{Narrative approach}

A narrative approach allows patients to tell their story during the assessment process and the health provider to be more fully present through active listening and thoughtful 
response. ${ }^{[24,49]}$ As a diagnostic tool, narrative becomes a method of ethical reasoning as it provides a nuanced view focused on the patient's story about health/illness situations that are context bound. ${ }^{[50]}$ Patients are viewed as moral agents who enact choices based on personal values. Thus, attention to narrative is important for making care decisions that are person-centered and support the values expressed by the patient through his/her story of an illness event. During the immersion course, students' received education on specific tools for improving their verbal and non-verbal skills. These included posture, eye contact, using silence to allow for thoughtful reflection, and allowing the patient to tell his/her story in order to capture the patient's illness experience. Using case scenarios about patients with multiple chronic conditions, students role played being the patient and the provider, with a focus on the introduction and first questions about the patient's presenting concern ("What brings you in today?" not "I see that you're here for ..."). Then, students performed an assessment with a standardized patient in which they used interpersonal communication techniques and a narrative approach. Again, students practiced how they engaged with patients, from entering the room, to allowing the patient to explain why they had sought treatment or to discuss their illness experience and using techniques to draw out the patient's story. After the standardized patient session, students received feedback from the standardized patient actor, as well as from faculty and fellow students. This process was designed to assist students to conduct patient assessments and frame decisions when developing patient-centered care plans.

\subsubsection{Mindfulness}

Caring patient-provider relationships require respect and highly developed communication skills. ${ }^{[4]}$ Mindfulness helps focus attention and draws on each individual's tacit knowledge that is situated in observation and practiced inductively. ${ }^{[51]}$ A healthcare provider who exercises curiosity about the way in which he/she delivers care can shift from a place of expert judge to thoughtful observer. Allowing oneself to be open in this way is what the philosopher Martin Buber referred to as being 'face to face' with another through confirmation of his/her presence, rather than being over and above. ${ }^{[52]}$ Such deep engagement allows for mutual dialogue and helps to shift the power differential that is often present between provider and patient and can be misused during a provider-patient encounter. ${ }^{[53]}$ During the immersion course, students learned about mindful practice and engaged in mindful activities such as focusing their attention on their breathing, and mindfully eating chocolate. They also completed group exercises in which they reflected on their experiences as both a patent and a provider, with a focus on how they or the provider were 'present' or 'not present' and the effect that had on their experience and their care (provided or received). Students were taught to tap into their own awareness, which can help them remove real and perceived barriers, a primary goal of patient-centered care. ${ }^{[54]}$ By teaching students to recognize the asymmetry that exists in provider-patient relationships ${ }^{[52]}$ while being mindful of social context and potential conflicts in values, ${ }^{[55]}$ students are better prepared to negotiate challenges that can occur in the delivery of care.

\subsubsection{Increased focus}

The study of art images can improve focus and patient assessment skills as the proficiencies necessary for locating meaning in a work of art are similar to those used during patient evaluation; ${ }^{[56-58]}$ each is contingent upon finding meaning and making informed judgments. Study and discussion of visual art images also promote the curiosity that is essential in developing well-thought out questions ${ }^{[43]}$ by enhancing listening skills and applying analysis when interacting with patients and other health providers. ${ }^{[59-61]}$ During the immersion course, students used an art critical method of analysis ${ }^{[62]}$ that sequentially asks students to describe and assess a work of art through a series of clearly defined steps. Students were able to begin with basic descriptions of the visual elements contained within the image and then build upon each other's value to make a first judgment. The final phase of this method of critical inquiry relies on the inclusion of contextually-grounded information about the artist's intent that allowed the students to make a more informed judgment and to discern meaning. This process was meant to enhance students' relationships with their patients and healthcare team members by developing their ability to really focus during provider-patient and provider-provider encounters.

IPE is designed to improve communication and teamwork in the delivery of quality and safe patient care. The inclusion of humanities-based subjects into an IPE curriculum can assist IPCP teams to recognize power, remove barriers that are intrinsic to each of the health professions, identify shared and differing values among team members, ${ }^{[63]}$ and strengthen provider-patient and provider-provider interactions through increased presence. ${ }^{[64]}$

\subsection{Study purpose}

The larger grant project included an immersion course and clinical practicum at an urban primary care clinic. The current study explored students' reactions to the humanitiesbased IPE curriculum using qualitative data from end-ofsemester focus groups and reflective journal entries regarding student perceptions of their IPCP experience in the clinical setting focused on the IPE core competencies. 


\section{MethodS}

\subsection{Participants}

Over the three years of the project, 64 students participated in the IPE immersion course and clinical practicum: $21 \mathrm{MSN}$ and/or DNP family nurse practitioner students, 16 graduate dental students, 17 graduate pharmacy students, and 10 master's level social work students. Most students were female $(78 \%, \mathrm{n}=50$; male $=22 \%, \mathrm{n}=14)$, and ranged in age from 22 to 62 years old $($ mean $=30, \mathrm{SD}=7.08)$. Few students identified themselves as Hispanic $(3 \%, \mathrm{n}=2)$. Most identified themselves as white $(81 \%, \mathrm{n}=52)$, with $8 \%(\mathrm{n}=$ 5) Black/African American, $8 \%(n=5)$ Asian, $2 \%(n=1)$ American Indian/Alaska Native, and 2\% $(\mathrm{n}=1)$ "more than one race".

\subsection{Data collection and analysis}

This study was approved by the University of MissouriKansas City Institutional Review Board. A one-hour focus group was held at the end of each of the five semesters of the project. Students participating in the grant were recruited by an email that asked them to participate in the focus group and provide feedback about the project. The project evaluator or evaluation coordinator conducted the focus groups; faculty were not present. At the beginning of each focus group, students were informed that participation in the focus group was voluntary and anonymous; no participant names or other identifying information were collected. Each focus group included ten questions about highlights of the program, roles and team development, and barriers and supports to IPCP (e.g., How did the program promote team development? Did anything hinder team development? What would you consider to be the greatest asset that [other professions] add to patient care? Give an example of how you used the knowledge or skills related to interpersonal communication with a patient). Focus groups were audio-recorded and then transcribed. A total of 45 students across the disciplines participated in the five focus groups (70\% response rate).

For the reflective journal entries, at the beginning of each semester, students were provided with a link to an anonymous online form, and were asked to respond to a series of nine questions based on their experiences in the clinic during the past week. The questions asked about the four IPEC competencies as well as communication with patients and with other providers (see section 1.3.1 Reflective Practice). A total of 35 students across all four disciplines provided reflective journal entries (54\% response rate).

Directed content analysis was used to analyze the data. ${ }^{[65]}$ In a directed content analysis, results are viewed from an underlying theory that is used to organize the data. For this study, the focus group transcripts and reflective journals en- tries were specifically analyzed for themes related to the outcomes that humanities-based curriculum components have been shown to affect (interpersonal communication, moral reasoning, interprofessional teams). Using that framework, the first author conducted the first round of coding, identifying text that represented or reflected outcomes related to the focus of the curriculum and developing initial coding categories. Then, these results were reviewed by all three authors to further categorize and code the identified text and to reach consensus on the themes represented.

\section{RESULTS}

Four major themes were identified that relate to the humanities-based curriculum. Student participants gained confidence in their abilities as health providers, improved their methods of communication and focus with patients, learned how to negotiate ethical situations in support of patient-centeredness, and grew as members of IPCP teams. Table 2 illustrates the emergent themes.

Table 2. Student perceptions of interprofessional practice following a humanities-based IPE curriculum and IPCP clinical rotation

\begin{tabular}{l}
\hline Themes \\
\hline Increased confidence as a healthcare provider \\
Interpersonal communication \\
Moral responsibility \\
Teamwork \\
\hline
\end{tabular}

\subsection{Theme 1: Increased confidence as a provider}

Students noted that they gained confidence in their ability to work with patients through focusing on the patient's story and in building more meaningful relationships. Student comments included:

"I felt confident in my ability to get background on a patient and ask the right questions to help guide the diagnosis and therapy."

"I felt more confident in the patient history taking and head-to-toe assessment."

"I saw a difference with the shaking of the hands and saying 'may I call you this?' ... sit down, eye level, all that... and after doing all that you get a small confidence. Just from that. Before the patient even starts talking."

\subsection{Theme 2: Interpersonal communication}

Interpersonal communication to improve patientcenteredness was an area of focus in the IPE curricular content, especially focused attention, clarity in message delivery, attention to non-verbal cues, and using reflection to engage more deeply 
with patients. Students commented on this during the focus groups and in their journals.

"After asking a patient about his smoking he was immediately defensive. I noticed his defensive words and body language almost made me defensive as well. I can see how easy it is for patients and providers to enter into unfruitful arguments. I used reflection and turned the conversation toward how smoking is related to the patient's chest pain. I learned that I still underestimate how very ready patients are to block any perceived attempt to get them to stop smoking. I learned the value of being patient instead of backing off too soon or immediately trying to get the patient to see the negative effects. I saw where a bit more evoking and double-sided reflection or summary might have been more helpful in this situation."

"Delivering the message in a way that is pertinent to the patient as opposed to information that is important to me."

“Asking 'unnecessary' questions can lead to important information."

"It seems that the more down to earth and personable you are with the patient the more receptive they are to your teaching and recommendations."

"Including the patient in the care plan, being more patientfocused, finding out what their goals are and including them in putting together their goals for treatment. How they expect us to move through the treatment plan."

"I used open ended questions and used silence to allow the patient to tell me their story. This allowed for much more information to be divulged."

\subsection{Theme 3: Moral responsibility}

Several students commented on how being present with a patient and being open to someone else's values was put into practice in the clinical setting as a result of participating in the curriculum.

"I spoke up on behalf of the patient when I thought something was being misunderstood."

"I did not agree with a medication therapy change with a patient; however, I verbalized my concern and as a team we acted professionally and put the patient's health first."

"I basically had to put aside my beliefs about premarital sex when talking to a patient... for me to lecture on why they should not have sex outside of marriage would not have built rapport, but rather could have been divisive."

"If my plan can't be implemented because they can't afford it or if they can't come back then my plan is just worth the paper."

"Something that I find to be the priority is not necessarily the patient's priority. So trying to reconcile as the provider. . the thing that I think is most important, the patient might not be willing or ready to accept that, that is a priority for their health."

\subsection{Theme 4: Teamwork}

This project was somewhat unique in its inclusion of four different graduate student groups, nurse practitioner, pharmacy, dentistry, and social work. Students participated in the immersion class together, and also saw clients together as teams in the urban-serving clinic. Building team skills was a theme in the focus groups and reflective journals.

"Communication with other providers allows for a more concrete and safer plan for the patients."

"Integrating the knowledge of all healthcare providers into a cohesive plan."

"Having open and comfortable dialogue helps with the flow of ideas."

"Definitely have checks and balance for all of us. ... it was nice, everybody's got each other's back."

"I felt it was always beneficial to have interprofessional teams and always creates a better knowledge base. I feel that these teams provide the best care to patients as a whole."

"The program got us to be interconnected which promoted team development. We saw how much we had to rely on each other to provide care to the patient."

\section{Discussion}

This project sought to identify alternative strategies for teaching nursing and other health professions students to work more collaboratively, increase moral reasoning, and improve relationship-building with their patients through reflective practice and communication strategies. Several humanitiesbased learning strategies were infused into an IPE curriculum that was paired with IPCP at an urban, primary care clinic serving underserved patients with multiple chronic conditions. Results of student focus groups and journal reflections as part of the project's evaluation focused on four themes, each of which has ties to the body of theory and research on the effects of humanities-based curriculum in health professions training. 


\subsection{Increased confidence as a provider}

Previous studies have examined how providing students with opportunities to practice reflection and interpersonal communication, both verbal and nonverbal, can increase confidence. ${ }^{[20,46]}$ This highlights the limits of the physical assessment and the need for health professionals to feel confident and competent in their history-taking skills. In the current study, students reported increased confidence in their ability to connect with patients and to understand their patients' narratives regarding their health/illness, which can lead to more accurate diagnosis and more effective treatment. This supports similar findings from other studies. Cooper, Spencer-Dawe, and Mclean ${ }^{[66]}$ reported on an IPE intervention program with health professions students, and found that students had increased confidence in their professional identities and abilities to function as members of interprofessional teams in a clinical setting. Also, in a study that addressed the need for increased experience and gaps in health professions education, Dornan and Bundy ${ }^{[67]}$ found that students' noted a need to build confidence when working with patients. Finally, in a study examining nurses' experiences as providers, self-confidence was identified as one of the most important personal factors that inform decision-making in clinical practice. ${ }^{[68]}$

\subsection{Interpersonal communication}

Patients report three reasons why it is important to them that healthcare providers listen: clinical assessment and diagnosis, empathy and healing, and promoting the provider/patient

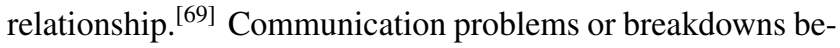
tween health professionals and patients can lead to diagnostic and other medical errors. ${ }^{[70]}$ According to Ross, ${ }^{[71]}$ training programs that involve actual patients and foster interpersonal communication and relationship-building can be beneficial in preparing students for clinical practice. Nurses in particular can benefit from developing effective interpersonal communication because they often serve as the patient's voice in working with the vulnerable, and utilization of these skills can also serve to support their own psychological and emotional well-being. ${ }^{[72]}$ Including humanities-based activities in health professions curricula can heighten students' ability to talk to and with patients, rather than talking at patients. ${ }^{[73]}$ Our students reported learning how to communicate with patients using more focused attention, reflecting back patients' speech, and providing clearer messaging regarding health status and possible treatment.

\subsection{Moral responsibility}

As healthcare and the treatment of health problems becomes increasingly complex and costly, patients are confronted with increasingly difficult decisions about what care and treat-

Published by Sciedu Press ment they accept and use, and health professionals may be at odds with one another about the best course of treatment based on their expertise. For example, patients with multiple chronic conditions often have to choose which medications or treatment regimens they can afford. Such decisions may seem indecipherable or irresponsible to health professionals, and may lead to negative or discriminatory beliefs about patients. Part of the IPEC ${ }^{[11]}$ competency of values/ethics is for healthcare providers to value and respect differences in patients as well as in other healthcare professionals. This includes adopting a definition of respect that goes beyond admiration for a particular individual to one that considers all persons in the clinical environment as being worthwhile of one's attention. ${ }^{[74]}$ Such openness can lead to moral courage and a willingness to explore alternative solutions, whether advocating on behalf of a patient, or negotiating conflicts among the clinical team. ${ }^{[75]}$ Humanities-based activities can assist students in their ethical reasoning and ability to provide patient-centered care where the patient's story and circumstances are considered in their care. ${ }^{[43,50]}$ Students in this project reported a number of examples in which they demonstrated moral responsibility, openness to other values, and ethical reasoning that preserved respect for patients and other health professionals.

\subsection{Teamwork}

Although the ideal of interprofessional team care has not caught up with actual practice in many areas, healthcare reform continues to move toward groups of healthcare providers serving patients in a holistic way that better meets their needs and improves care for the population (e.g., patientcentered health homes, accountable care organizations). Nurses and other healthcare professionals must have significant education and experience in working on teams. ${ }^{[1,12]}$ In a study on interdisciplinary teamwork, Nancarrow et al. ${ }^{[76]}$ identified a number of attributes that can lead to effective team function including, communication, skill mix of individual members, supportive work environment, and respect and understanding of each individuals' role and contributions to the team. Nurses are essential to the delivery of team-based care and health professions programs must find meaningful opportunities to build interprofessional care teams that include novel models in teaching IPE in preparing nurses and other health professionals to transition from training to professional practice. ${ }^{[77]}$ Health professions students who participate in humanities-based activities report they learn from other students and professionals and appreciate their perspectives, as well as learning about group process and collaboration. ${ }^{[50,59,78]}$ In this study, students reported increased ability to work as members of IPCP teams in which the expertise of all healthcare providers is respected. They gained 
knowledge about each other's professions, roles, and scope of practice, which can assist them in informally developing relationships and connections in clinical practice even where formal teams are not being used.

\subsection{Limitations}

The focus of this study was to examine student perceptions of interprofessional practice following the humanities-based IPE education curriculum and IPCP rotation. A limitation of the study is that we are not able to state that the humanitiesbased IPE curriculum caused the student perceptions. The directed content analysis strategy aimed to highlight themes related to the humanities-based curriculum components, with the understanding that the IPE environment and clinical rotation may also have affected the findings. However, the wider literature on humanities-based curricula has shown similar changes in health professions education students. Despite the lack of a comparison group, students were not told about the humanistic-based curriculum until they had been chosen for the project, so self-selection bias should not have occurred.

\section{RECOMMENDATIONS}

This project brought together advanced practice nursing and other health professions education, IPE, and a humanitiesbased curriculum. The Institute of Medicine's Future of Nursing ${ }^{[12]}$ report includes a number of key messages targeted in this project: having nurses practice to their full scope, increasing levels of and quality of nursing education, and needing nurses to be full partners in healthcare and among healthcare professionals. More broadly, there have been a number of recent calls to enhance health professions education to focus more on developing transformative learning experiences, ${ }^{[17]}$ teaching the ability to critically observe pa- tients and capture their narrative experience of health, ${ }^{[65,79]}$ and assisting students to become more empathic and communicate more clearly. ${ }^{[37,80]}$ Studies have shown that including humanities-based educational components in health professions curriculum leads to those outcomes, ${ }^{[24,43,44]}$ which may in turn lead to better patient outcomes and safety. Moreover, the IPE core competency domains of interpersonal communication, values/ethics, and teams/teamwork ${ }^{[11]}$ particularly can be targeted using humanities based activities. ${ }^{[1]}$

The results of this study captured enhanced student skills and confidence following the humanities-informed IPE training and clinical practicum. IPE will continue to be a method for improving fragmentation in healthcare and for increasing patient safety and care through enhanced provider focus, communication and teamwork. Thus, the inclusion of the humanities into IPE education and practice can assist with strengthening presence, promoting moral imagination, and evoking a reciprocity of caring. We recommend that humanities-based education strategies be infused into nursing and other health professions education, especially IPEfocused curriculum. Moreover, although there is a large literature on the effects of humanities-based strategies, future research should focus on the intersection of those humanitiesbased strategies with IPE, and push evaluation to examine patient outcomes.

\section{ACKNOWLEDGEMENTS}

This work was supported by \#1D09HP25926-01-00 Advanced Nursing Education Grant from the Health Services and Resources Administration

\section{CONFlicts OF INTEREST Disclosure}

The authors declare that there is no conflict of interest.

\section{REFERENCES}

[1] Department of Education, Science and Training (DEST). 2002. Employability skills for the future. Canberra: Commonwealth of Australia.

[2] Lowden K, Hall S, Elliott D, et al. Employer's perceptions of the employability skills of new graduates. London: Edge Foundation.

[3] Blaxell R, Moore C. 2012. Connecting academic and employability skills and attributes. In: Developing student skills for the next decade. Proceedings of the 21st Annual Teaching Learning Forum. Perth: Murdoch University. Available from: http://otl . curtain.edu/ au/tlf/tlt2012/refereed/blaxell.pdf

[4] Baggs JG, Schmidt MH, Mushlin AI, et al. Association between nurse-physician collaboration and patient outcomes in three intensive care units. Critical Care Medicine. 1999; 27: 1991-1998. http://dx.doi.org/10.1097/00003246-199909000-00045

[5] Andrew N. Professional identity in nursing: Are we there yet? Nurse Education Today. 2012; 32: 846-849. PMid:22531469. http:
$/ /$ dx.doi.org/10.1016/j.nedt.2012.03.014

[6] Andrew N, Tolsen D, Ferguson D. Building on Wenger: Communities of practice in nursing. Nurse Education Today. 2008; 28 : 246-252. PMid:17599697. http://dx.doi.org/10.1016/j.ned t.2007.05.002

[7] Wenger E, McDermott R, Snyder W. A guide to managing knowledge: Cultivating communities of practice. Boston, MA: Harvard Business School Press. 2002.

[8] Institute of Medicine. 1999. To err is human. Washington, DC: The National Academies Press.

[9] Institute of Medicine. 2011. The future of nursing: Leading change, advancing health. Washington, DC: The National Academies Press.

[10] Reinke LF, Hammer B. The role of interprofessional collaboration in creating and supporting health care reform. American Journal of Respiratory and Critical Care Medicine. 2011; 184: 863- 
864. PMid:22003143. http://dx.doi.org/10.1164/rccm.20 1108-1392ED

[11] Interprofessional Education Collaborative Expert Panel. 2011. Core competencies for interprofessional collaborative practice: Report of an expert panel. Washington, DC: Interprofessional Education Collaborative.

[12] Institute of Medicine. 2001. Crossing the quality chasm: A new health system for the 21st century. Washington, DC: The National Academies Press.

[13] Institute of Medicine. 2003. Health professions education: A bridge to quality. Washington, DC: The National Academies Press.

[14] Welch KA. A medical humanities course: A pertinent pause on the medical beat. Journal for the Assembly of Expanded Perspectives on Learning. 2001; 6: 40-51.

[15] Macnaughton J. The humanities in medical education: Context, outcomes and structures. Medical Humanities. 2000; 26: 23-30. http://dx.doi.org/10.11.1136/mh.26.1.23

[16] Quintero GA. Medical education and the healthcare system - why does the curriculum need to be reformed? Biomed Central. 2014; 12 : 213. http://dx.doi.org/10.1186/s12916-014-0213-3

[17] Frenk J, Chen L, Bhutta AA, et al. Health professionals for a new century: Transforming education to strengthen health systems in an interdependent world. Lancet. 2010; 376: 1923-1958. http://dx.doi.org/10.1016/S0140-6736(10)61854-5

[18] Cribb A. The diffusion of the health agenda and the fundamental need for partnerships in medical education. Medical Education. 2000; 34: 916-920. http://dx.doi.org/10.1046/j.1365-2923.20 $00.00793 . x$

[19] Kolb DA. 1984. Experiential learning. Englewood Cliffs, NJ: Prentice-Hall.

[20] Clark PG. What would a theory of interprofessional education look like? Some suggestions for developing a theoretical framework for teamwork training. Journal of Interprofessional Care. 2006; 20 : 577-589. PMid:17095437. http://dx.doi.org/10.1080/13561 820600916717

[21] Dellasega C, Milone-Nuzzo P, Curci KM, et al. The humanities interface of nursing and medicine. Journal of Professional Nursing. 2007; 23: 174-179. PMid:17540321. http://dx.doi.org/10: $1016 / j$.profnurs .2007 .01 .006

[22] Bruderle B, Valiga T. The arts and humanities: A creative approach to developing nurse leaders. Journal of Holistic Nursing Practice. 1991; 9: 68-74. http://dx.doi.org/10.1097/00004650-199 410000-00011

[23] Hermann MK. Linking liberal and professional learning in nursing education. Liberal Education. 2004; 90: 42-47.

[24] Hermann M, Wright R. The current nature of integration of the humanities in baccalaureate nursing education. Chester, PA: Widener University. 2002.

[25] Lazenby M. On the humanities in nursing. Nursing Outlook. 2012; 61: e9-e14. PMid:22884719. http://dx.doi.org/10.1016/j.o utlook.2012.06.018

[26] Yu A. The encounter of nursing and the clinical humanities: Nursing education and the spirit of healing. Humanities. 2014; 3: 660-674. http://dx.doi.org/10.2290/h3040660

[27] McKie A. Using the arts and humanities to promote a liberal nursing education: Strengths and weaknesses. Nurse Education Today. 2012 32: 803-810. PMid:22579881. http://dx.doi.org/10.1016/j .nedt. 2012.04.014

[28] Cassell EJ. The place of humanities in medicine. Hastings-onHudson, NY: Institute of Society, Ethics and the Life Sciences. 1984.

[29] Butts JB, Rich KL. Nursing ethics: Across the curriculum and into practice. Sudbury, MA: Jones \& Bartlett Publishers. 2008.
[30] Hall JM, Powell J. Understanding the person through narrative. Nursing Research and Practice. 2011. http://dx.doi.org/10.1155 /2011/293837

[31] Shapiro J. Toward the clinical humanities: How literature and the arts can help shape humanism and professionalism in medical education. Arnold P. Gold Foundation Humanism in Medicine. 2014. Available from: http://humanism-in-medicine.org/category/human ities-in-medicne/

[32] Fesmire S. John Dewey \& moral imagination: Pragmatics in ethics. Bloomington, IN: Indiana University. 2003.

[33] Friedman LD. The precarious position of the medical humanities in the medical school curriculum. Academic Medicine. 2002; 77: 320-322. http://dx.doi.org/10.1097/00001888-20020 4000-00011

[34] Self DI. The educational philosophies behind medical humanities programs in the United States. Theoretical Medicine. 1993; 14: 221-229. http://dx.doi.org/10.1007/BF00995164

[35] Nazarlo R. Medical humanities as tools for the teaching of patientcentered care. Journal of Hospital Medicine. 2009; 4: 512-514. PMid:19824102. http://dx.doi.org/10.1002/jhm. 480

[36] Razavi D, Delvaux N, Marchal S, et al. Does training increase the use of more emotionally laden words by nurses when talking with cancer patients? A randomised study. British Journal of Cancer. 2002; 87: 1-7. PMid:12085247. http://dx.doi.org/10.1038/sj.bj c. 6000412

[37] Street RL, Makoul G, Arora NK, et al. How does communication heal? Pathways linking clinician-patient communication to health outcomes. Patient Education and Counseling. 2009; 74: 295301. PMid:19150199. http://dx.doi.org/10.1016/j.pec.2 008.11 .015

[38] Bailey JE. Does health information technology dehumanize healthcare? Journal of Ethics. 2011; 13: 181-185.

[39] Weiner M, Biondich P. The influence of information technology on patient-physician relationships. Journal of General Internal Medicine. 2006; 21(Suppl 1): S35-S39. http://dx.doi .org/10.1111/j.1 $525-1497.2006 .00307 . x$

[40] Barnard A, Sandelowski M. Technology and humane nursing care: (Ir)reconcilable or invented difference? Journal of Advanced Nursing 2000; 34: 367-375

[41] The Experts. (2013, April 13). How to improve doctorpatient communication. The Wall Street Journal. Available from: http://www.wsj.com/articles/SB100014241278873 24050304578411251805908228

[42] Hojat M. Ten approaches for enhancing empathy in health and human services cultures. Journal of Health and Human Services Administration. 2009; 31: 412-450. PMid:19385420.

[43] Jones DS. A complete medical education includes the arts and humanities. Journal of Ethics. 2014; 16: 636-641.

[44] Smith RL, Bailey M, Hydo SK, et al. All the voices in the room: Integrating humanities in nursing education. Nursing Education Perspectives. 2004; 25: 278-283.

[45] Schwartz AW, Abramson JS, Wojnocich I, et al. Evaluating the impact of the humanities in medical education. Mount Sinai Journal of Medicine. 2009; 76: 372-360. PMid:19642151. http://dx.doi.o $\mathrm{rg} / 10.1002 / \mathrm{msj} .20126$

[46] Kennedy DM, Fasolino JP, Gullen DJ. Improving the patient experience through provider communication skills building. Patient Experience Journal. 2014; 1: 56-60.

[47] Brookfield SD. Becoming a critically reflective teacher. San Francisco, CA: Jossey-Bass. 1995. 
[48] Ahlzén R. Medical humanities-arts and humanistic science. Medicine, Health Care and Philosophy. 2007; 10: 385-393. PMid:17624812. http://dx.doi.org/10.1007/s11019-007-9081-3

[49] Charon R. Narrative medicine: Honoring the stories of illness. Oxford: Oxford University Press. 2006.

[50] Clark PG. Narrative in interprofessional education and practice: Implications for professional identity, provider-patient communication and teamwork. Journal of Interprofessional Care. 2014; 28: 3439. PMid:24224865. http://dx.doi.org/10.3109/13561820. 2013.853652

[51] Epstein RM. Mindful practice. Journal of the American Medical Association (JAMA). 1999; 282: 833-839. http://dx.doi.org/1 $0.1001 /$ jama. $282,9.833$

[52] Scott JG, Scott RG, Miller WL, et al. Healing relationships and the existential philosophy of Martin Buber. Philosophy, Ethics, and Humanities in Medicine. 2009; 4: 11. PMid:19678950. http: //dx.doi.org/10.1186/1747-5341-4-11

[53] Goodyear-Smith F, Buetow S. Power issues in the doctor-patient relationship. Health Care Analysis. 2001; 9: 449-62. PMid:11874258. http://dx.doi.org/10.1023/A:1013812802937

[54] Stewart M, Brown JB, Donner A, et al. The impact of patient-centered care on outcomes. Journal of Family Practice. 2000; 49: 796-804.

[55] Shattell M. Nurse-patient interaction: A review of the literature. Journal of Clinical Nursing. 2004; 13: 714-722. PMid:15317511. http://dx.doi.org/10.1111/j.1365-2702.2004.00965.x

[56] Hamblen KA. An art criticism questioning strategy within the framework of Bloom's Taxonomy. Studies in Art Education. 1984; 26: 41-50. http://dx.doi.org/10.2307/1320799

[57] Nkanginieme KEO. Clinical diagnosis as a dynamic cognitive process: Application of Bloom's Taxonomy for educational objectives in the cognitive domain. Medical Education Online. 1997: 1-6. Available from: http://www. utmb.edu/meo

[58] Schaff PB, Isken S, Tager RM. From contemporary art to core clinical skills: Observation, interpretation, and meaning-making in a complex environment. Academic Medicine. 2011; 88: 12721276. PMid:21869657. http://dx.doi .org/10.1097/ACM. Ob0 $13 \mathrm{e} 31822 \mathrm{c} 161 \mathrm{~d}$

[59] Kalitzkus V, Matthiessen PF. Narrative-based medicine: Potential, pitfalls and practice. Permanente Journal. 2009; 13: 80-86.

[60] Karkabi K, Wald HS, Castel OC. The use of abstract paintings and narratives to foster reflective capacity in medical educators: A multinational faculty development workshop. Medical Humanities. 2013; 40: 44-48. PMid:24273319. http://dx.doi.org/10.1136/med hum-2013010178

[61] Miller A, Grohe M, Khoshbin S, et al. From the galleries to the clinic: Applying art museum lessons to patient care. Journal of Medical Humanities. 2013; 34: 433-438. PMid:24014232. http: //dx.doi.org/10.1007/s10912-013-9250-8

[62] Anderson TA. A structure for pedagogical art criticism. Studies in Art Education. 1998; 30: 28-38. http://dx.doi.org/10.2307/1 320649

[63] Shaver JL. Interdisciplinary education and practice: Moving from reformation to transformation. Nursing Outlook. 2005; 53: 5758. PMid:15858522. http://dx.doi.org/10.1016/j.outlook .2005 .02 .002

[64] Hall P, Brajtman S, Weaver L, et al. Learning collaborative teamwork: An argument for incorporating the humanities. Journal of Interprofessional Care. 2014; 28: 519-525. PMid:24828622. http: //dx.doi.org/10.3109/13561820.2014.915513

[65] Hsieh HF, Shannon SE. Three approaches to qualitative content analysis. Qualitative Health Research. 2005; 15: 1277-1288.
PMid:16204405. http://dx.doi.org/10.1177/10497323052 76687

[66] Cooper H, Spencer-Dawe E, Mclean E. Beginning the process of teamwork: Design, implementation and evaluation of an interprofessional education intervention for first year undergraduate students. Journal of Interprofessional Care. 2005; 19: 492-508. PMid:16308172. http://dx.doi.org/10.1080/13561820500 215160

[67] Dornan T, Bundy C. What can experience add to early medical education? Consensus survey. BMJ. 2004; 329: 834. PMid:15472265. http://dx.doi.org/10.1136/bmj.329.7470.834

[68] Hagbaghery MA, Salsali M, Ahmadi F. The factors facilitating and inhibiting effective clinical decision-making in nursing: A qualitative study. BMC Nursing. 2004; 3(1): 2. PMid:15068484 http://dx.doi.org/10.1186/1472-6955-3-2

[69] Jagosh J, Boudreau JD, Steinert Y, et al. The importance of physician listening from the patients' perspective: Enhancing diagnosis, healing, and the doctor-patient relationship. Patient Education and Counseling. 2011; 85: 369-374. PMid:21334160. http: //dx.doi.org/10.1016/j.pec.2011.01.028

[70] Graber ML, Franklin N, Gordon R. Diagnostic error in internal medicine. Archives of Internal Medicine. 2005; 165: 1493-1499. PMid:16009864. http://dx.doi.org/10.1001/archinte.16 5.13 .1493

[71] Ross L. Facilitating rapport through real patient encounters in health care professional education. Australasian Journal of Paramedicine. 2013; 10(4): 5 .

[72] Vertino K. Effective interpersonal communication: A practical guide to improve your life. OJIN: The Online Journal of Issues in Nursing. 2014; 19(3): 1. http://dx.doi.org/10.3912/0JIN.Vol19No0 $3 \mathrm{Man} 01$

[73] Bleakley A, Marshall R. Can the science of communication inform the art of the medical humanities? Medical Education. 2013; 47: 126-133. PMid:23323651. http://dx.doi .org/10.1111/medu . 12056

[74] Beach MC, Duggan PS, Cassel CK, et al. What does 'respect' mean? Exploring the moral obligation of health professionals to respect patients. Journal of General Internal Medicine. 2007; 22: 692-695. PMid:17443381. http://dx.doi.org/10.1007/s1160 6-006-0054-7

[75] Murray JS. Moral courage in healthcare: Acting ethically even in the presence of risk. OJIN: The Online Journal of Issues in Nursing. 2010; 15(3): 2. http://dx.doi.org/10.3912/OJIN . Vol15NoO $3 \mathrm{Man} 02$

[76] Nancarrow SA, Booth A, Ariss S, et al. Ten principles of good interdisciplinary team work. Human Resources for Health. 2013; 11(1): 19. PMid:23663329. http://dx.doi.org/10.1186/147 8-4491-11-19

[77] National League for Nursing. 2015. Interprofessional collaboration in education and practice: A living document of the National League for Nursing. Available from: http://www.nln.org/docs/default-source/defaul t-document-library/ipe-ipp-vision.pdf?sf vrsn=14

[78] Klugman CM, Peel J, Beckmann-Mendez D. Art rounds: Teaching interprofessional students visual thinking strategies at one school. Academic Medicine. 2011; 86: 1266-1271. PMid:21869658. http: //dx.doi.org/10.1097/ACM. 0b013e31822c1427

[79] Wellberry C, McAteer RA. The art of observation: A pedagogical framework. Academic Medicine. 2015; 90: 1624-1630. PMid:26164640. http://dx.doi.org/10.1097/ACM. 0000000 000000801 
[80] Miller E, Balmer D, Hermann M, et al. Sounding narrative medicine: studying students' professional identity development at Columbia University College of Physicians and Surgeons. Academic Medicine. 2014; 89: 335-342. PMid:24362390. http://dx.doi.org/10.10 97/ACM. 0000000000000098
[81] Pardue KT. A framework for the design, implementation, and evaluation of interprofessional education. Nurse Educator. 2015; 40: 10-15. PMid:25330345. http://dx. doi.org/10.1097/NNE. 000 0000000000093 